Г.В. Габруссв, І.Ю. Габрусєва, Т.Б. Пиндус

Тернопільський національний технічний університет імені Івана Пулюя

\title{
ТИСК ПАРАБОЛІЧНОГО ШТАМПА НА ПОПЕРЕДНЬО НАПРУЖЕНИЙ ШАР
}

Наведено розв'язок контактної задачі про взаємодію параболічного штампа із попередньо напруженим шаром. Система парних інтегральних рівнянь, цио при цьому отримується, розв'язується за допомогою подання шуканих функцій напружень у вигляді відрізку ряду за функціями Бесселя з невідомими коефіцієнтами та подальшим отриманням скінченних систем лінійних алгебраӥчних рівнянь для ӥх знаходження. На основі отриманого напружено-деформованого стану проаналізовано вплив форми штампа на контактні напруження.

Ключові слова: контактна взаємодія, контактні напруження, параболічний штамп, шар, початкові деформачіi

\section{Г.В. Габрусев, И.Ю. Габрусева, Т.Б. Пындус ДАВЛЕНИЕ ПАРАБОЛИЧЕСКОГО ШТАМПА НА ПРЕДВАРИТЕЛЬНО НАПРЯЖЕННЫЙ СЛОЙ}

\begin{abstract}
Приведено решение контактной задачи о взаимодействии параболического итампа из предварительно напряжённым слоем. Система парных интегральных уравнений относительно неизвестной функции напряжений решается при помощци представления этой функции отрезком ряда по функциям Бесселя из неизвестными коэффициентами и сведением их к системе линейных алгебраических уравнений для нахождения коэффициентов. На основании полученного напряжсенно-деформированного состояния проанализировано влияние формы итампа на контактные напряжения.

Ключевые слова: контактное взаимодействие, контактные напряжения, параболический итамп, слой, начальные деформации
\end{abstract}

\section{H. Habrusiev, I. Habrusieva, T. Pyndus PRESSURE OF PARABOLIC PUNCH ON PRESTRESSED LAYER}

While designing modern engineering structures in many cases of engineering practice it is important to know the distribution of stresses and strains occurring on bodies contact taking into account initial stresses and strains and contact body shapes. The stress-strain state (SSS) of prestress layer while contacting with parabolic punch is investigated in this paper. The problem is solved within the limits linear elasticity theory. The required SSS is presented in the form of Hankel integral. Satisfaction of the boundary problem conditions results in paired integral equation relatively to the function determining the contact stresses under the die. These equations are solved by means of numerical method. The influence of the die shape and initial layer strains on the contact stresses value and the vertical displacements of the stressed body points is investigated.

Key words: contact interaction, contact stresses, parabolic punch, layer, initial deformation

Актуальність теми. Визначення контактних напружень і деформацій при взаємодії жорстких штампів з пружною плитою є важливим завданням при проектуванні деталей машин та елементів споруд. Зокрема, при оцінці міцності залізобетонних перекриттів, монолітних фундаментних плит у будівництві, дорожнього покриття тощо. Щоб мінімізувати похибку розрахунків, необхідно враховувати максимальну кількість чинників, що впливають на контактну взаємодію. Початкові деформації, від яких безпосередньо залежать контактні напруження та переміщення, є одним із ключових факторів.

Аналіз відомих результатів досліджень. Питаннями взаємодії тіл із наявними залишковими деформаціями займалося багато вчених, зокрема й вітчизняних. У загальному постановка таких задач вимагає залучення апарату нелінійної теорії пружності, проте при досить великих початкових деформаціях можна обмежитися ії лінеаризованим варіантом [1].

Незважаючи на збільшення кількості досліджень, присвячених контактній взаємодії тіл 3 попередньо напруженим станом [2-4], задача про тиск параболічного штампа на закріплену на жорсткій основу попередньо напружену товсту плиту досі не розв'язана для стисливих i нестисливих тіл у загальному вигляді при довільній структурі пружного потенціалу.

Постановка задачі. Постановку та розв'язання задачі проведемо в рамках лінеаризованої теорії пружності. Розглянемо жорсткий штамп утворений обертанням вітки параболи із параметром $R$ та відрізка прямої, яка перпендикулярна до осі параболи і проходить через іï вершину, навколо спільної осі, що паралельна до осі параболи. Штамп поступально без обертання та тертя втискується постійною силою $P$ у попередньо напружений шар товщиною $h$, закріплений на жорсткій основі. 


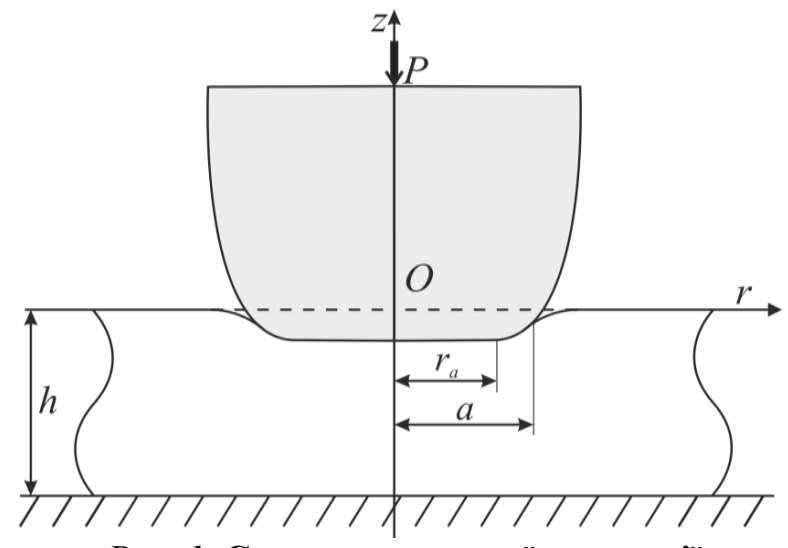

Puc. 1. Схема контактної взаємодії параболічного штампа та шару.
Виберемо циліндричну систему координат $(O, r, \theta, z)$ так, щоб координатна площина $(r, O, \theta)$ збігалася 3 верхньою граничною площиною шару, а вісь $O z-3$ віссю симетрії штампа (рис. 1).

Вважатимемо відомим радіус ділянки контакту $a$. Виходячи із формулювання задачі, можна описати функцію, обертанням графіка якої навколо осі $\mathrm{Oz}$ утворено штамп

$$
W(r)=\left\{\begin{array}{l}
0,0 \leq r \leq r_{a} ; \\
\frac{1}{2 R}\left(r-r_{a}\right)^{2}, r_{a}<r .
\end{array}\right.
$$

Граничні умови поставленої задачі мають вигляд

$$
\begin{gathered}
Q_{3 r}(r, 0)=0,0 \leq r<\infty ; \\
Q_{33}(r, 0)=0, a \leq r ; \\
u_{3}(r, 0)=\omega(r), 0 \leq r \leq a ; \\
u_{r}(r,-h)=0,0 \leq r<\infty ; \\
u_{3}(r,-h)=0,0 \leq r<\infty .
\end{gathered}
$$

Функція $\omega(r)$ описує переміщення точок верхньої граничної площини пружного шару на ділянці його контракту з жорстким штампом. А тому, виходячи із вигляду функції $W(r)$, можна записати:

$$
\omega(r)=\left\{\begin{array}{l}
\omega(a)-\frac{\left(a-r_{a}\right)^{2}}{2 R}, 0 \leq r \leq r_{a} ; \\
\omega(a)-\frac{1}{2 R}\left[\left(a-r_{a}\right)^{2}-\left(r-r_{a}\right)^{2}\right], r_{a}<r \leq a .
\end{array}\right.
$$

Розв'язання задачі. Будемо вважати залишкові напруження, наявні у шарі, однорідними. Тому можна використати наступні вирази для компонентів тензора напружень i вектора переміщень [1]

$$
\begin{aligned}
& Q_{3 r}(r, z)=-c_{31} \int_{0}^{\infty} \alpha^{3}\left\{A_{1} \operatorname{sh}(\alpha z)+A_{2}\left[s_{0} \operatorname{sh}(\alpha z)+\alpha z \operatorname{ch}(\alpha z)\right]+\right. \\
& \left.+B_{1} \operatorname{ch}(\alpha z)+B_{2}\left[s_{0} \operatorname{ch}(\alpha z)+\alpha z \operatorname{sh}(\alpha z)\right]\right\} J_{1}(\alpha r) d \alpha ; \\
& Q_{33}(r, z)=c_{33} \int_{0}^{\infty} \alpha^{3}\left\{A_{1} \operatorname{ch}(\alpha z)+A_{2}[\operatorname{sch}(\alpha z)+\alpha z \operatorname{sh}(\alpha z)]+\right. \\
& \left.+B_{1} \operatorname{sh}(\alpha z)+B_{2}[\operatorname{ssh}(\alpha z)+\alpha z \operatorname{ch}(\alpha z)]\right\} J_{0}(\alpha r) d \alpha ; \\
& u_{r}(r, z)=-\int_{0}^{\infty} \alpha^{2}\left\{A_{1} \operatorname{ch}(\alpha z)+A_{2}[\operatorname{ch}(\alpha z)+\alpha z \operatorname{sh}(\alpha z)]+\right. \\
& \left.+B_{1} \operatorname{sh}(\alpha z)+B_{2}[\operatorname{sh}(\alpha z)+\alpha z \operatorname{ch}(\alpha z)]\right\} J_{1}(\alpha r) d \alpha ; \\
& u_{3}(r, z)=m \int_{0}^{\infty} \alpha^{2}\left\{A_{1} \operatorname{sh}(\alpha z)+A_{2}\left[s_{1} \operatorname{sh}(\alpha z)+\alpha z \operatorname{ch}(\alpha z)\right]+\right. \\
& \left.+B_{1} \operatorname{ch}(\alpha z)+B_{2}\left[s_{1} \operatorname{ch}(\alpha z)+\alpha z \operatorname{sh}(\alpha z)\right]\right\} J_{0}(\alpha r) d \alpha .
\end{aligned}
$$


Константи $c_{31}, c_{33}, m, s, s_{0}, s_{1}$ залежать від характеру пружного потенціалу та підбираються у кожному випадку окремо [1]. Невідомі функції $A_{1}, B_{1}, A_{2}, B_{2}$ визначаються 3 граничних умов задачі.

На верхній граничній площині шару при $z=0$ зі співвідношень (7) - (8) отримаємо

$$
\begin{gathered}
Q_{33}(r, 0)=c_{33} \int_{0}^{\infty} \alpha^{3}\left\{A_{1}+A_{2} s\right\} J_{0}(\alpha r) d \alpha ; \\
Q_{3 r}(r, 0)=-c_{31} \int_{0}^{\infty} \alpha^{3}\left\{B_{1}+B_{2} s_{0}\right\} J_{1}(\alpha r) d \alpha ; \\
u_{3}(r, 0)=m \int_{0}^{\infty} \alpha^{2}\left\{B_{1}+B_{2} s_{1}\right\} J_{0}(\alpha r) d \alpha .
\end{gathered}
$$

На нижній граничній площині шару при $z=-h$ маємо

$$
\begin{gathered}
u_{r}(r,-h)=-\int_{0}^{\infty} \alpha^{2}\left\{A_{1} \operatorname{ch}(\alpha h)+A_{2}[\operatorname{ch}(\alpha h)+\alpha h \operatorname{sh}(\alpha h)]+\right. \\
\left.-B_{1} \operatorname{sh}(\alpha h)-B_{2}[\operatorname{sh}(\alpha h)+\alpha h \operatorname{ch}(\alpha h)]\right\} J_{1}(\alpha r) d \alpha ; \\
u_{3}(r,-h)=m \int_{0}^{\infty} \alpha^{2}\left\{-A_{1} \operatorname{sh}(\alpha h)+A_{2}\left[-s_{1} \operatorname{sh}(\alpha h)-\alpha h \operatorname{ch}(\alpha h)\right]+\right. \\
\left.+B_{1} \operatorname{ch}(\alpha h)+B_{2}\left[s_{1} \operatorname{ch}(\alpha h)+\alpha h \operatorname{sh}(\alpha h)\right]\right\} J_{0}(\alpha r) d \alpha .
\end{gathered}
$$

Вимагаючи виконання граничної умови (1), із рівності (10) отримуємо співвідношення між функціями $B_{1}$ та $B_{2}$

$$
B_{1}+B_{2} s_{0}=0 ; \Rightarrow B_{1}=-s_{0} B_{2} .
$$

Підставивши (14) у співвідношення (12) - (13) та задовольнивши граничні умови (4) - (5), матимемо систему рівнянь відносно невідомих $A_{1}$ та $A_{2}$

$$
\left\{\begin{array}{l}
A_{1} \operatorname{ch}(\alpha h)+A_{2}[\operatorname{ch}(\alpha h)+\alpha h \operatorname{sh}(\alpha h)]=B_{2}\left[\alpha h \operatorname{ch}(\alpha h)+\left(1-s_{0}\right) \operatorname{sh}(\alpha h)\right] \\
A_{1} \operatorname{sh}(\alpha h)+A_{2}\left[s_{1} \operatorname{sh}(\alpha h)+\alpha h \operatorname{ch}(\alpha h)\right]=B_{2}\left[\left(s_{1}-s_{0}\right) \operatorname{ch}(\alpha h)+\alpha h \operatorname{sh}(\alpha h)\right] .
\end{array}\right.
$$

Розв'язавши (15), отримуємо вирази для $A_{1}$ та $A_{2}$ через функцію $B_{2}$

$$
\begin{aligned}
& A_{1}=\frac{(\alpha h)^{2}-s_{1}+s_{0} c h^{2}(\alpha h)-s_{0} s_{1} s h^{2}(\alpha h)}{\left(s_{1}-1\right) \operatorname{ch}(\alpha h) \operatorname{sh}(\alpha h)+\alpha h} B_{2} ; \\
& A_{2}=\frac{\left(s_{1}-s_{0}\right) \operatorname{ch}^{2}(\alpha h)-\left(1-s_{0}\right) s h^{2}(\alpha h)}{\left(s_{1}-1\right) \operatorname{ch}(\alpha h) \operatorname{sh}(\alpha h)+\alpha h} B_{2} .
\end{aligned}
$$

3 урахуванням співвідношень (14) та (16) вирази (9) та (11) набувають вигляду:

$$
\begin{array}{r}
Q_{33}(r, 0)=c_{33}\left(s-s_{0}\right) \int_{0}^{\infty} \frac{\alpha^{3} B_{2}}{\Delta(\alpha)} J_{0}(\alpha r) d \alpha ; \\
u_{3}(r, 0)=m\left(s_{1}-s_{0}\right) \int_{0}^{\infty} \alpha^{2} B_{2} J_{0}(\alpha r) d \alpha ; \\
\Delta(\alpha)=\frac{\left(s_{1}-1\right) \operatorname{sh}(\alpha h) \operatorname{ch}(\alpha h)+\alpha h}{(\alpha h)^{2}-s_{1}+\left(s_{0}+s s_{1}-s s_{0}\right) c h^{2}(\alpha h)-\left(s_{0} s_{1}+s-s s_{0}\right) s h^{2}(\alpha h)} .
\end{array}
$$

Задовольнивши граничну умову (2), на основі (17) матимемо

$$
c_{33}\left(s-s_{0}\right) \int_{0}^{\infty} \frac{\alpha^{3} B_{2}}{\Delta(\alpha)} J_{0}(\alpha r) d \alpha=0, a \leq r .
$$


Уведемо невідому функцію $x(r), \quad 0 \leq r \leq a$, за допомогою якої продовжимо співвідношення (19) на проміжок $0 \leq r<\infty$

$$
c_{33}\left(s-s_{0}\right) \int_{0}^{\infty} \frac{\alpha^{3} B_{2}}{\Delta(\alpha)} J_{0}(\alpha r) d \alpha=x(r) \eta(a-r), 0 \leq r<\infty,
$$

де $\eta(r)$ - функція Гевісайда.

Функція $x(r)$ визначає розподіл контактних напружень під штампом. Урахувавши їх неперервність, а також рівність нулю на границі області контакту (при $r=a$ ), представимо $x(r)$ у вигляді відрізка узагальненого ряду Фур'є за функціями $J_{0}\left(\frac{\lambda_{n}}{a} r\right)$

$$
Q_{33}(r, 0)=x(r)=\sum_{n=1}^{N} a_{n} J_{0}\left(\frac{\lambda_{n}}{a} r\right), 0 \leq r \leq a,
$$

де $\lambda_{n}, n=\overline{1, N}$ - додатні корені функції Бесселя $J_{0}\left(\lambda_{n}\right)=0 ; a_{n}$-невідомі коефіцієнти.

Застосувавши формулу обернення інтегрального перетворення Ганкеля до співвідношення (20) та врахувавши представлення (21), отримуємо

$$
\frac{\alpha^{2} B_{2}}{\Delta(\alpha)}=\frac{1}{c_{33}\left(s-s_{0}\right)} \sum_{n=1}^{N} a_{n} \int_{0}^{a} r J_{0}\left(\frac{\lambda_{n}}{a} r\right) J_{0}(\alpha r) d r .
$$

Увівши позначення

$$
\Psi_{n}(\alpha)=\int_{0}^{a} r J_{0}\left(\frac{\lambda_{n}}{a} r\right) J_{0}(\alpha r) d r
$$

із (22) отримуємо

$$
\alpha^{2} B_{2}=\frac{\Delta(\alpha)}{c_{33}\left(s-s_{0}\right)} \sum_{n=1}^{N} a_{n} \Psi_{n}(\alpha) .
$$

Підставивши співвідношення (23) у рівність (18), отримаємо

$$
u_{z}(r, 0)=k_{1} \sum_{n=1}^{N} a_{n} \int_{0}^{\infty} \Delta(\alpha) \Psi_{n}(\alpha) J_{0}(\alpha r) d \alpha, k_{1}=\frac{m\left(s_{1}-s_{0}\right)}{c_{33}\left(s-s_{0}\right)} .
$$

Вимагаючи виконання граничної умови (3) та врахувавши (24), знаходимо

$$
\begin{gathered}
k_{1} \sum_{n=1}^{N} a_{n} \int_{0}^{\infty} \Delta(\alpha) \Psi_{n}(\alpha)\left\{J_{0}(\alpha r)-J_{0}(\alpha a)\right\} d \alpha=\omega^{*}(r), \\
\omega^{*}(r)=\left\{\begin{array}{l}
-\frac{1}{2 R}\left(r_{a}-a\right)^{2}, 0 \leq r \leq r_{a} ; \\
\frac{1}{2 R}\left[\left(r_{a}-r\right)^{2}-\left(r_{a}-a\right)^{2}\right], r_{a}<r \leq a .
\end{array}\right.
\end{gathered}
$$

Помноживши співвідношення (25) на $r J_{0}\left(\frac{\lambda_{q}}{a} r\right)$ та проінтегрувавши отримані вирази по $r$ від 0 до $a$, матимемо

$$
\begin{gathered}
\sum_{n=1}^{N} a_{n} \int_{0}^{\infty} \Delta(\alpha) \Psi_{n}(\alpha)\left[\Psi_{q}(\alpha)-K_{q} J_{0}(\alpha a)\right] d \alpha=\frac{w_{q}}{k_{1}}, q=\overline{1, N} ; \\
K_{q}=\int_{0}^{a} r J_{0}\left(\frac{\lambda_{q}}{a} r\right) d r ; \quad w_{q}=\int_{0}^{a} r \omega^{*}(r) J_{0}\left(\frac{\lambda_{q}}{a} r\right) d r .
\end{gathered}
$$

Уведемо позначення

$$
a_{n}=\frac{1}{2 R k_{1}} a_{n}^{*}
$$


3 урахуванням якого із (26) отримуємо систему $N$ лінійних алгебраїчних рівнянь відносно невідомих $a_{n}^{*}$.

Вираз для визначення фокального параметра $R$, що входить до співвідношення (27), знаходимо з умови рівноваги штампа

$$
2 \pi \int_{0}^{a} r \sigma_{z z}(r, 0) d r=-P
$$

Підставивши у (28) вирази (21) та (27), визначаємо

$$
\frac{1}{2 R}=\frac{k_{1} P}{2 \pi} \frac{-1}{\sum_{n=1}^{N} a_{n}^{*} K_{n}},
$$

3 урахуванням (29), (27) із (21) матимемо формулу для визначення розподілу контактних напружень під штампом

$$
Q_{33}(r, 0)=-\frac{P}{2 \pi} \frac{\sum_{n=1}^{N} a_{n}^{*} J_{0}\left(\frac{\lambda_{n}}{a} r\right)}{\sum_{n=1}^{N} a_{n}^{*} K_{n}} .
$$

На підставі співвідношень (18) та (27) знаходимо формулу для визначення вертикальних переміщень точок верхньої граничної площини шару

$$
u_{3}(r, 0)=-\frac{k_{1} P}{2 \pi} \frac{\sum_{n=1}^{N} a_{n}^{*} \int_{0}^{\infty} \Delta(\alpha) \Psi_{n}(\alpha) J_{0}(\alpha r) d \alpha}{\sum_{n=1}^{N} a_{n}^{*} K_{n}} .
$$

Числовий приклад. На рис. 2 та 3 наведено графіки функцій $\sigma^{*}=\frac{Q_{33}(r, 0)}{P}$ та $u^{*}=\frac{u_{3}(r, 0)}{P}$, що характеризують розподіл контактних напружень (30) та вертикальних переміщень (31). У якості числового прикладу розглянуто випадок наявності у плиті пружного потенціалу гармонічного типу [1] та наявності в основі штампа плоскої ділянки при $h=1, a=1$. Крива 1 відповідає $r_{a}=0$, крива $2-r_{a}=0.2$, а крива $3-r_{a}=0.5$.

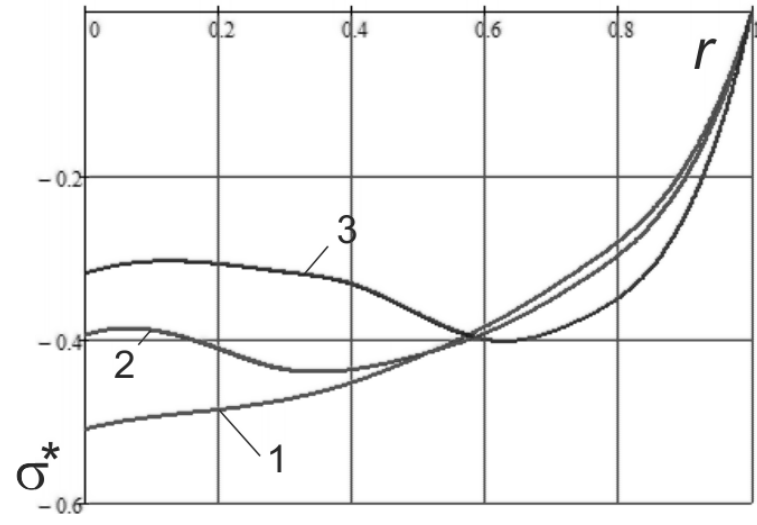

Рис. 2. Розподіл контактних напружень

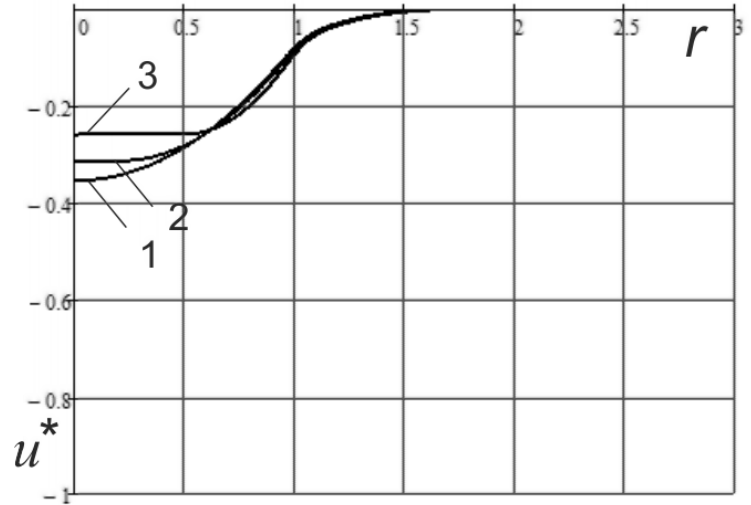

Рис. 3. Вертикальні переміщення

Висновки. У рамках лінеаризованої теорії пружності подано постановку та розв'язання осесиметричної контактної задачі про взаємодію параболічного штампа із попередньо напруженим шаром, закріпленим на жорсткій основі. Проаналізовано вплив наявності в основі жорсткого штампа плоскої ділянки. Встановлено, що форма штампа суттєво впливає на величину та характер розподілу контактних напружень. Зокрема, у параболічних штампів без плоскої ділянки в основі екстремальні значення контактних напружень виникають у центрі області 
контакту. Поява плоскої ділянки спричиняє зсув точок екстремуму до краю ділянки контакту та зменшує їх абсолютну величину. Якщо $r_{a}=0.2 a$ (рис. 1), то абсолютна величина контактних напружень зменшується приблизно на $10 \%$, якщо $r_{a}=0.5 a-$ на $12 \%$. Вертикальні переміщення при цьому зменшуються на $9 \%$ та $11 \%$ відповідно. Одержані в роботі результати можуть використовуватися при розробці методик зменшення контактних напружень або вертикальних переміщень при проектуванні різного роду конструкцій.

\section{Список використаної літератури:}

1. Гузь О. М. Контактна взаємодія пружних тіл з початковими напруженнями: Навч. посібник / Гузь О. М., Бабич С. Ю., Рудницький В. Б. - К: Вища школа, 1995. - 304 с.

2. Шелестовський Б. Г. Взаємодія кільцевого штампа із попередньо напруженим шаром у випадку потенціалу Бартенєва-Хазановича / Б. Г. Шелестовський, І. Ю. Габрусєва // Вісник ТНТУ. - 2010. T. 15, №3. - C. $14-22$.

3. Gabrusseva I. Yu. Contact interaction of a circular punch with a preliminarily stressed isotropic layer / B.G. Shelestovs`kyi, I.Yu. Gabrusseva // Journal of mathematical sciences. - 2012. - Vol.186, No.1. - P. 48 -60 .

4. Габрусєва I. Ю. Контактна задача для параболічного штампа та попередньо напруженого півпростору / І. Ю. Габрусєва // Міжвузівський збірник «Наукові нотатки». - 2015. - Вип. 51. - С. 231 - 236.

\section{Рещензенти:}

Окрепкий Богдан Степанович, кандидат фізико-математичних наук, доцент, доцент кафедри прикладної математики Тернопільського національного економічного університету

Марущак Павло Орестович, доктор технічних наук, професор, завідувач кафедри автоматизації технологічних процесів і виробництв Тернопільського національного технічного університету імені Івана Пулюя 